\title{
Temperature distribution in concrete structure under the action of fire using Ansys software
}

\author{
Chuc Nguyen Trong ${ }^{1,2, *}$, Chinh Mai Viet ${ }^{2,3}$ and Bach Luu Xuan ${ }^{4}$ \\ ${ }^{1}$ Moscow State University of Civil Engineering, Yaroslavskoe shosse, 26, Moscow, 129337, Russia \\ ${ }^{2}$ Le Quy Don Technical University, Ha Noi, Vietnam \\ ${ }^{3}$ Kumoh National Institute of Technology, Gumi, Gyeongbuk, Korea \\ ${ }^{4}$ Tri Dung Construction Transportation Joint Stock Company, Dong Nai, Vietnam
}

\begin{abstract}
In the last few decades, fires caused serious damage in civil engineering, especially in the high-rise building, factories, offices, etc. Usually the structures are built with fireproof materials such as concrete. It is a complex material, and its properties can change dramatically when exposed to high temperatures. This problem requires engineers to study and evaluate the effect of the fire in the structure. This paper studies the effect of the fire on the temperature distribution in concrete structure using Finite Element Ansys software. The results will be used to provide reference data for concrete structures under the action of fire. The research is an intermediate task to convert the fire activity in a structural model into the real impact in calculating model. It plays significant role in calculating structural model for counteracting the action of fire.
\end{abstract}

\section{Introduction}

This has caused problems for safe evacuation and rescue activities, and in some instances lead to the collapse of buildings. According to the Report of International of Fire and Rescue Services [1], there were over 1,600,000 fires reported in the World. This number indicates that, on average, one structure catches fire every 62 seconds. Fires in 2017 caused 3763 deaths and $\$ 10.7$ billion in property damage. Many of these fires are initiated by explosions, which are often due to ignition of a dust cloud or gas leak, unintended/uncontrolled chemical reaction in an industrial plant, or a malicious act. The air-pressure wave resulting from an explosion and the intense heat generated by a subsequent fire produce extreme loads that often badly damage buildings and other structures.

Fire is a very complex phenomenon which can take many forms and involves different kinds of chemical reactions. Fire is usually represented by a temperature-time curve, which gives the average temperature reached during a fire in a small size compartment or in the furnaces used for fire resistance tests. International standards are based on the standard fire defined by the heat exposure given by the Eurocode (Part 1-2) or ISO 834 curve [2-3]. It also can be shown by the research of Anthony D. Ariyanayagam and Mahen Mahendran [4].

*Corresponding author: ntchuc.mta198@gmail.com 


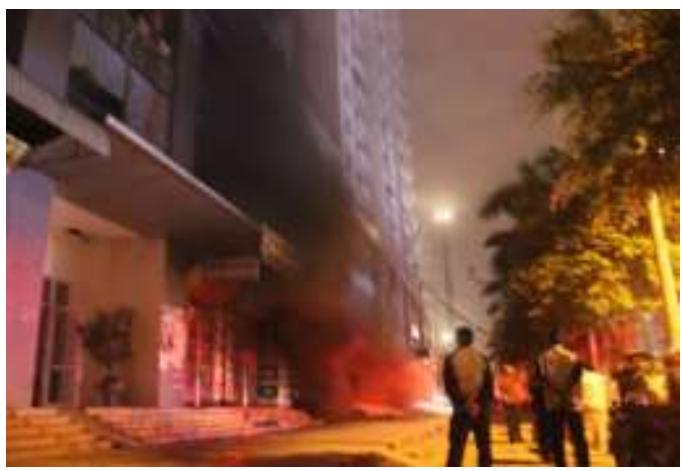

Fig. 1. A fire in the apartment building in Hanoi, Vietnam.

These time-temperature curves were derived using mass and energy balance equations, heat release rates, and curve fitting to temperature profiles obtained from compartment tests. The literature on post-flashover time-temperature curves shows that it is very difficult to envisage the time-temperature profile of a fire in a compartment.

The nature of concrete-based structures means that they generally perform very well in the fire. However, concrete is fundamentally a complex material, and its properties can change dramatically when exposed to high temperatures. The principal effects of fire on concrete are a loss of compressive strength, and spelling - the forcible ejection of material from the surface of a member. The response to realistic fires of whole concrete structures presents yet greater challenges due to the interactions of structural elements, the impact of complex small-scale phenomena at full scale, and the spatial and temporal variations in exposures, including the cooling phase of the fire [5].

Many structural engineers have not traditionally been involved in the analysis or design of building fire safety. When they have been, their focus has generally been on structural fire protection and, with some exceptions, their scope has been limited to ensuring compliance with prescriptive building code requirements for the fire resistance ratings of different building elements. In order to design structures, in many types, for resisting fire, the structural engineer must understand the behavior of these structures under fire action. In this research, the authors model the thermal distribution in reinforced concrete beam and floor under the effect of flame. Based on the results, some important conclusions will be expressed, which play a significant role in designing structures to resist fire action.

\section{Methods}

The governing partial differential heat conduction equation in three dimensions for the temperature [6-9].

$$
\frac{\partial}{\partial x}\left(k_{x} \frac{\partial T}{\partial x}\right)+\frac{\partial}{\partial y}\left(k_{y} \frac{\partial T}{\partial y}\right)+\frac{\partial}{\partial z}\left(k_{z} \frac{\partial T}{\partial z}\right)+q=\rho c \frac{\partial T}{\partial \tau},
$$

where: $\mathrm{T}$ - the material temperature $\left({ }^{0} \mathrm{C}\right)$;

$\mathrm{k}_{\mathrm{x}}, \mathrm{k}_{\mathrm{y}}, \mathrm{k}_{\mathrm{z}}$ - thermal conductivity coefficient $\left(\mathrm{W} / \mathrm{m}^{0} \mathrm{C}\right)$, dependent on temperature in $\mathrm{x}$, $\mathrm{y}$, and $\mathrm{z}$ direction, respectively;

$\mathrm{q}$ - heat generation rate $\left(\mathrm{W} / \mathrm{m}^{3}\right)$;

c - specific heat coefficient $\left(\mathrm{J} / \mathrm{kg}^{0} \mathrm{C}\right)$;

$\rho$ - density $\left(\mathrm{kg} / \mathrm{m}^{3}\right)$; 
There are two main types of boundary conditions which can be applied to solve equation (1):

$$
T=T_{p} \text { and }-k \frac{\partial T}{\partial n}=h\left(T_{s}-T_{f}\right)
$$

where: $T_{p}$ - the nodal temperatures on the concrete surfaces $\left({ }^{0} \mathrm{C}\right), \tau$-time $(\mathrm{s})$;

$\mathrm{n}$ - the outward direction normal to the surface;

$\mathrm{h}$ - heat transfer coefficient $\left(\mathrm{W} / \mathrm{m}^{2} .{ }^{0} \mathrm{C}\right)$;

$\mathrm{T}_{\mathrm{s}}$ - temperatures at the boundary nodal points $\left({ }^{0} \mathrm{C}\right)$;

$\mathrm{T}_{\mathrm{f}}$ - the ambient temperature $\left({ }^{0} \mathrm{C}\right)$.

The FEM transient thermal analysis to find out the temperature field in the concrete constructions is expressed as shown in equation (3) [10-11].

$$
[K]\{T\}+[C]\left\{\frac{\partial T}{\partial \tau}\right\}=[F],
$$

The first order derivative of the temperature distribution achieved from the Euler equation is described in equation (4) [12].

$$
\left\{\frac{\partial T}{\partial \tau}\right\}=\frac{1}{\Delta \tau}\left[\left\{T\left(\tau_{n}\right)-T\left(\tau_{n-1}\right)\right\}\right],
$$

Then, equation (3) can be written in the form of equation (5):

$$
[K]\{T\}+\frac{[C]}{\Delta \tau}\left[\left\{T\left(\tau_{n}\right)-T\left(\tau_{n-1}\right)\right\}\right]=[F],
$$

where: $[\mathrm{K}]$ - conductance matrix containing the thermal conductivity terms $\mathrm{k}$ and heat exchange coefficients $h$;

$[C]$ - the specific heat matrix, considering increased internal energy;

$\{\mathrm{F}\}$ - thermal load vector;

$\left\{\frac{\partial T}{\partial \tau}\right\}$ - nodal temperature rate vector $\frac{\partial T}{\partial \tau}$;

$\Delta \tau=\tau_{\mathrm{n}}-\tau_{\mathrm{n}-1}-$ time step calculations.

\section{Calculation model and Results}

\subsection{Input data}

The cross-sections of the beam and floor are depicted in Figure 3. The material of the beams and columns is selected with the elastic module of concrete, $E_{c}=2.65 .10^{4} \mathrm{~N} / \mathrm{mm}^{2}$. We aim at investigating the effects of fire action on these subjects is determined in Table 1.

Table 1. The cross-sections of the floor and beam [13].

\begin{tabular}{|c|c|c|}
\hline No & Subject & Cross-section (mm) \\
\hline 1 & Concrete floor & $4000 \times 200$ \\
\hline 2 & Beam & $300 \times 500$ \\
\hline
\end{tabular}

Base on ISO-834 standard, fire curve is accepted to represent via two factors: time and temperature [14]. 


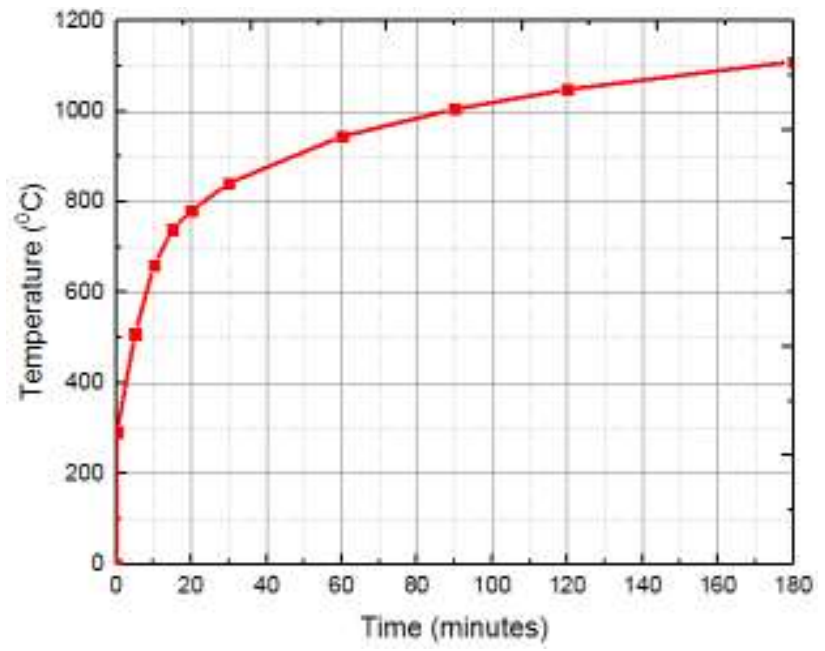

Fig. 2. Temperatures versus time curves.

The initial temperature of concrete surface is set $25^{\circ} \mathrm{C}\left(\mathrm{T}_{0}=25^{\circ} \mathrm{C}-\right.$ ambient temperature) is applied to the above concrete face by convection with a film coefficient of $25 \mathrm{~W} / \mathrm{m}^{2} .{ }^{0} \mathrm{C}[15]$.

The property of concrete material is determined in Table 2.

Table 2. Material properties in analysis.

\begin{tabular}{|c|l|c|}
\hline No & \multicolumn{1}{|c|}{ Property } & $\begin{array}{c}\text { Concrete } \\
\text { material }\end{array}$ \\
\hline 1 & Thermal conduction coefficient, $\mathrm{W} /\left(\mathrm{m} .{ }^{0} \mathrm{C}\right)$ & 1.2 \\
\hline 2 & Specific heat, $\mathrm{kJ} /\left(\mathrm{kg} .{ }^{0} \mathrm{C}\right)$ & 1.0 \\
\hline 3 & Density, $\mathrm{kg} / \mathrm{m}^{3}$ & 2400 \\
\hline 4 & Convection coefficient, $\mathrm{W} /\left(\mathrm{m}^{2} \cdot{ }^{0} \mathrm{C}\right)$ & 25 \\
\hline 5 & Thermal expansion coefficient, $1 /{ }^{0} \mathrm{C}$ & $1.10^{-5}$ \\
\hline 6 & Poisson's ratio & 0.2 \\
\hline
\end{tabular}

\subsection{Size of the model}

To create the finite element models in Ansys software, it requires some multiple and complicated tasks that affect immediately results. In the research, 70 solid thermal model is used for concrete structures. This element can be effective for 3D thermal analysis, steadystate or transient thermal analysis. The cross-section of concrete beam is $300 \times 500 \mathrm{~mm}$, the cross section of concrete floor is $4000 \times 200 \mathrm{~mm}$. The finite element mesh of the model is shown in Figure 3 - 4. 


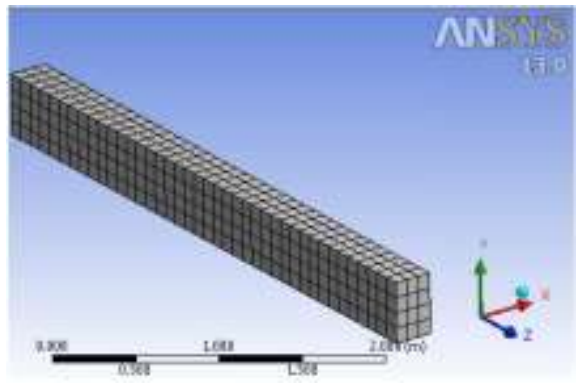

Fig. 3. Finite element mesh of concrete beam $300 \times 500 \mathrm{~mm}$

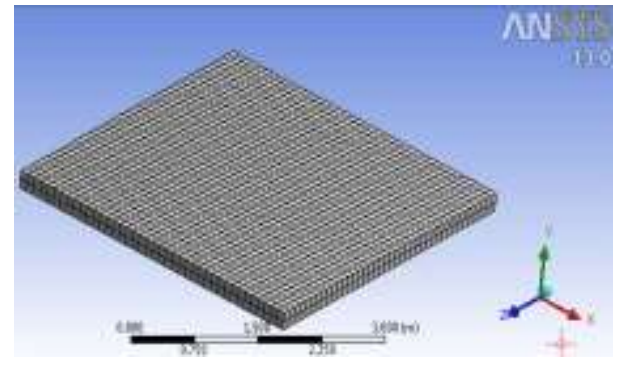

Fig. 4. Finite element mesh of concrete floor $4000 \times 200 \mathrm{~mm}$

\subsection{Analysis results}

By using Ansys workbench software, the temperature distribution in concrete structures under the fire action is shown in Figures $5-8$.

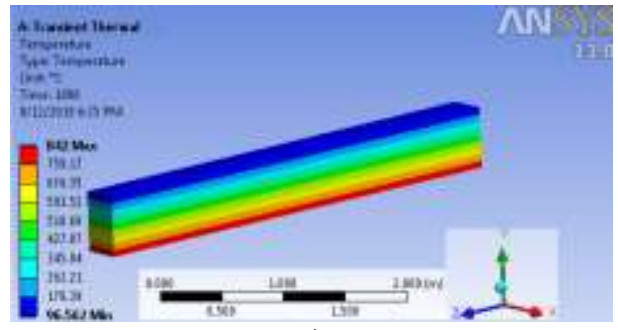

a)

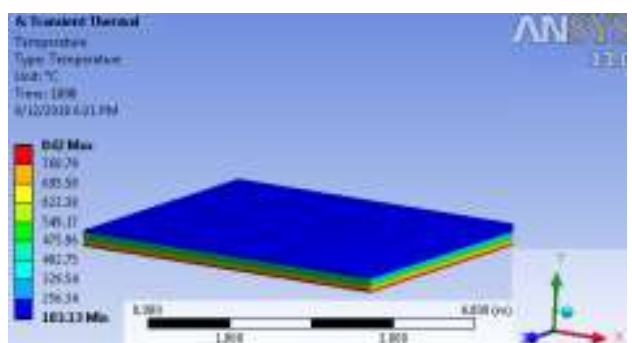

b)

Fig. 5. Temperature distribution in the concrete beam (a) and concrete floor (b) at 30 minutes.

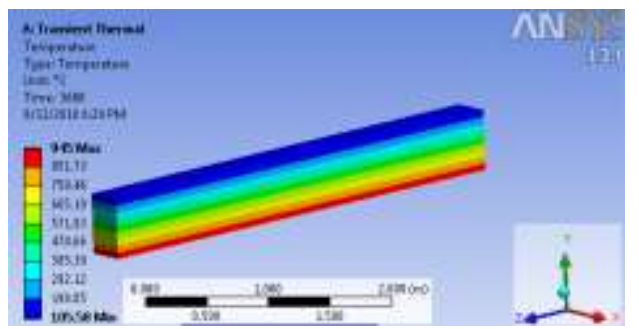

a)

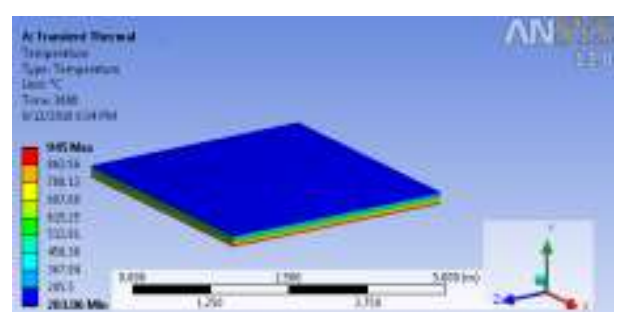

b)

Fig. 6. Temperature distribution in the concrete beam (a) and concrete floor (b) at 60 minutes.

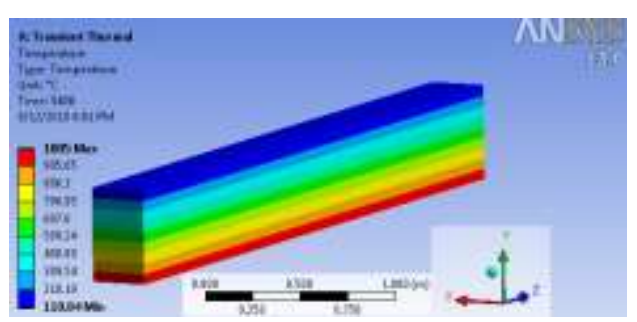

a)

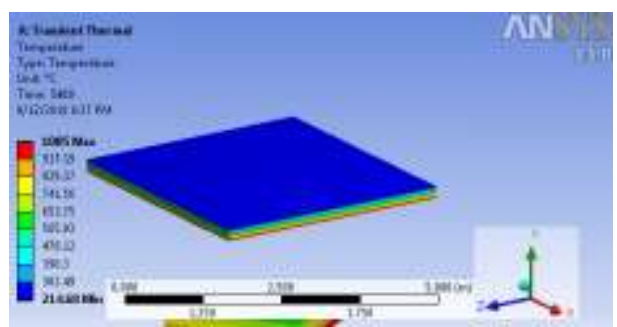

b)

Fig. 7. Temperature distribution in the concrete beam (a) and concrete floor (b) at 90 minutes. 


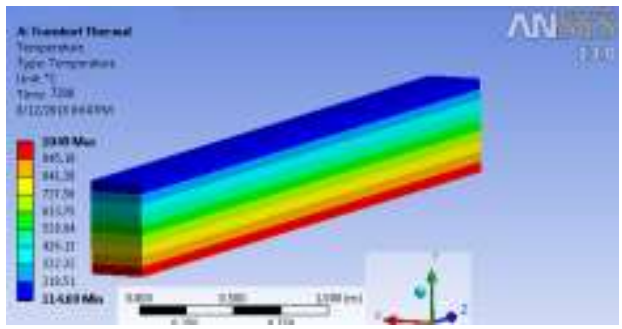

a)

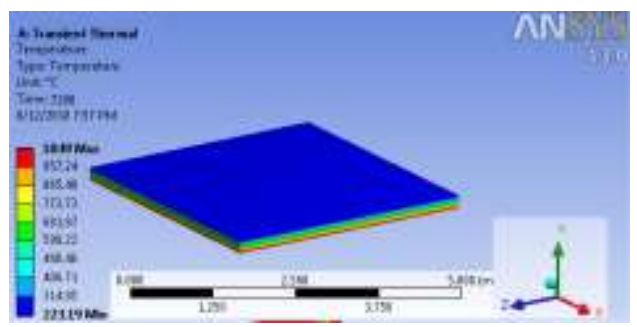

b)

Fig. 8. Temperature distribution in the concrete beam (a) and concrete floor (b) at 120 minutes.

Temperature distribution in concrete beams and concrete floors tend to increase with temperature fire.

Due to less thickness of floor, the temperature distribution in the concrete floor is higher than the temperature distribution in the concrete beam.

Time survey of the fire from 30 to 120 minutes leads to increased temperature from $842^{\circ} \mathrm{C}$ to $1049^{\circ} \mathrm{C}$. The highest temperature of the concrete beam increased from $96.56^{\circ} \mathrm{C}$ to $114.69^{\circ} \mathrm{C}$ and the highest temperature of the concrete floor increased from $183.13^{\circ} \mathrm{C}$ to $223.19^{\circ} \mathrm{C}$.

Figure 9 - 10 shows the temperature distribution on height of concrete beam and thickness of the concrete. It is a linear relationship.
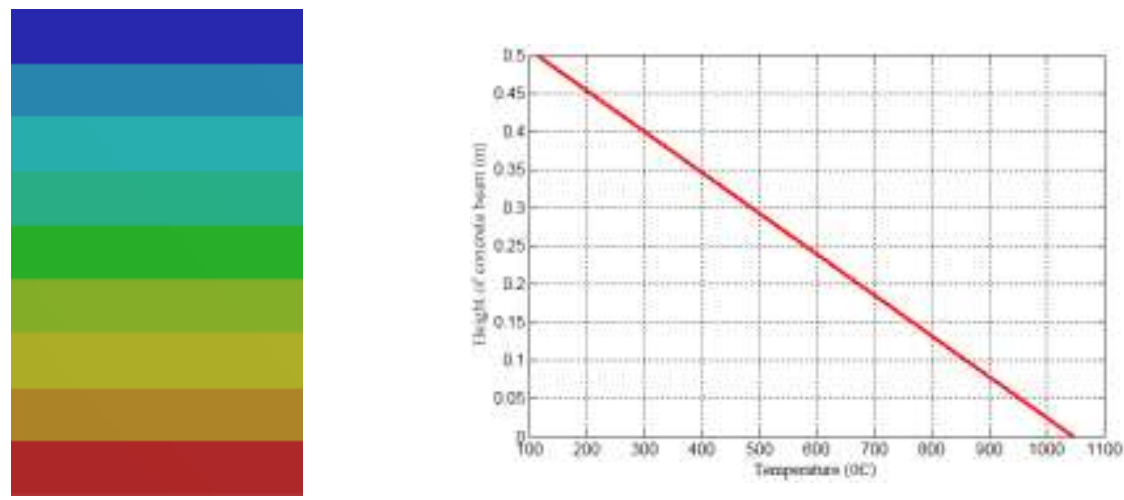

Fig. 9. Temperature distribution on height of concrete beam.
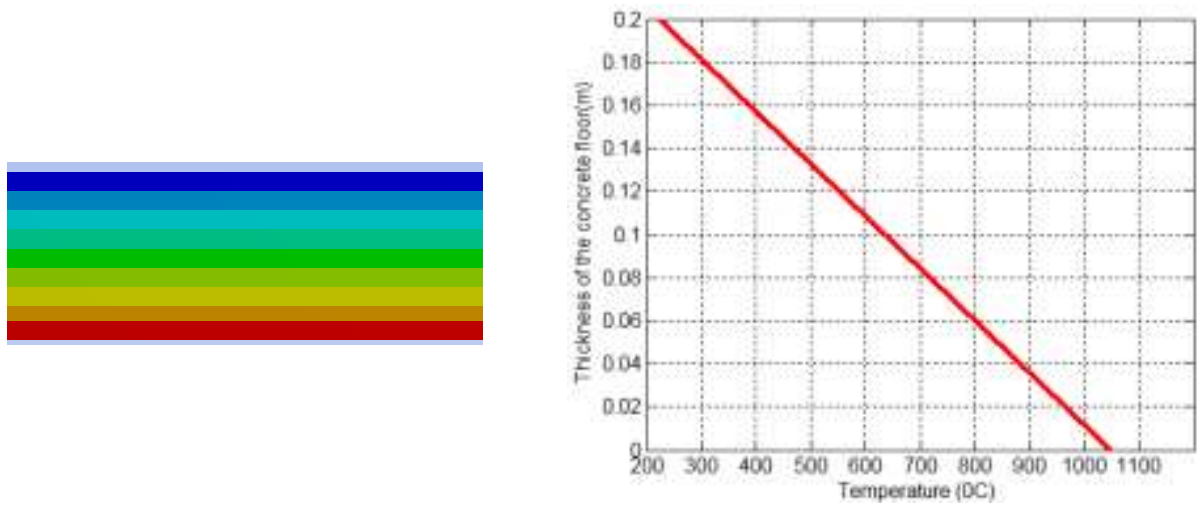

Fig. 10. Temperature distribution on thickness of the concrete floor 


\section{Conclusion}

These results of the research can be used in calculating fire resistance in the concrete structure by using famous software like Ansys.

Determine the temperature distribution on the beams and on the floor below the fire is the important principle to evaluate the damage of reinforcement cover, especially layers of concrete reinforced.

When the time went up from 30 to 120 minutes, the temperature of fire increased from $842^{\circ} \mathrm{C}$ to $1049^{\circ} \mathrm{C}$. As a result of this process, the highest temperature of the concrete beam and the concrete floor raised from $96.56^{\circ} \mathrm{C}$ to $114.69^{\circ} \mathrm{C}$ and from $183.13^{\circ} \mathrm{C}$ to $223.19^{\circ} \mathrm{C}$, respectively.

Based on the law of temperature distribution, it is possible to determine the variation of mechanical properties of materials such as elastic modulus, strength, strain, etc. Calculation of the level of material strength at the moment during the fire is an intermediate task to convert the effect of fire action into real data in structural model, which is significant in designing construction to resist the fire.

\section{References}

1. N.N. Brushlinsky, M. Ahrens, S.V. Sokolov, P. Wagner, Nati. Commit. CTIF of Rus., Ger., USA. 23 (2018)

2. BS EN 1991-1-2: 2002, standard Eurocode 1: Actions on structures (British, 2002)

3. B. Jacob, A. Balaji, E. John, Amer. J. of Eng. Res. (AJER) 3 (2015)

4. A.A. Deloge, M.Mahen, Pro. of the 19th Inter. CIB Wor. Buil. Cong. (2013)

5. V. Kudryashov, N.T. Kien, A. Lupandin, Saf. of Tech. Envir. 3 (2012)

6. N. Aniskin, N.T. Chuc, M. Web of Conf. 196, 04059 (2018) doi.org/10.1051/matecconf/201819604059

7. J.A. Purkiss, Fire safety engineering design of structures (Oxford, 2007)

8. X. Zhang, C. Gong, Inter. Conf. on Mana. and Ser. Sci. (2009)

9. T.V. Lam, N.T. Chuc, B. Bulgakov, P.N. Anh, Web of Conf. 196, 04017 (2018) doi.org/10.1051/matecconf/201819604017

10. J. Selih, A.C.M. Sousa, Trans. on Eng. Sci. 12 (1996)

11. H.D. Mahale, S.B. Kandekar, J. of Eng. Res. and Appl. 6, 5 (2016)

12. M. Musmar, A. Shatnawi and N. Shatarat, ARPN J. of Eng. and Appl. Sci. 12, 23 (2017)

13. Y. Zandi, O. Burnaz and A. Durmus, Res. J. of Envir. and Ear. Sci. 4, 8 (2012)

14. G.A. Khoury, Pro. in Struc. Eng. and Mater. 2, 4 (2000)

15. L. Dahmani, M. Kouane, Inter. J. of C. and Envir. Eng. 6, 11 (2012) 